\title{
SUBJETIVIDADES
}

Edição Especial:

A Psicanálise e as Formas do Político

e-ISSN: 2359-0777

\section{INTOLERÂNCIA: FRONTEIRAS E PSICANÁLISE}

Intolerance: Frontiers and Psychoanalysis

Intolerancia: Fronteras y Psicoanálisis

\section{L'Intolérance: Frontières et Psychanalyse}

DOI: $10.5020 / 23590777 . r s . v 18 i E s p .6739$

\section{Miriam Debieux Rosa (Lattes)}

Professora Livre-Docente no Instituto de Psicologia da Universidade de São Paulo.

\section{Diego Amaral Penha (Lattes)}

Doutorando no Departamento de Psicologia Clínica do Instituto de Psicologia da Universidade de São Paulo - Laboratório de Psicanálise e Sociedade.

\section{Patrícia do Prado Ferreira (Lattes)}

Pós-Doutoranda no Departamento de Psicologia Clínica do Instituto de Psicologia da Universidade de São Paulo - Laboratório de Psicanálise e Sociedade.

\section{Resumo}

Vivemos em um tempo em que o mal-estar se radicaliza e se expressa em manifestações de intolerância. Buscamos sustentar a intolerância como fruto do mal-estar presente na constituição das fronteiras nos campos social e subjetivo e nos modos de circulação entre territórios. Há na intolerância uma posição do sujeito pautada pela ignorância consentida das complexidades em jogo - sociais, políticas, históricas, culturais, linguísticas ou psíquicas. Nessa operação, há um tripé: a paranoia como matriz do conhecimento da lógica liberal, que mantem o imaginário de uma sociedade sob ameaça e incita o medo da alteridade como afeto político central e o ódio como coadjuvante. Em uma lógica identitária, que se presta a certa 'obturação' da aventura do desejo, o outro se torna sinônimo de inimigo ou objeto de uma indiferença radical que preconiza o seu desaparecimento. A ignorância obscurece a ambivalência que está no cerne do sujeito e da agressividade que habita cada um. Mas, se de um lado, o ódio ou o desejo de destruição são constitutivos; de outro, é de escolha e responsabilidade do sujeito colocá-lo em ato.

Palavras-chave: intolerância; política; psicanálise; ódio; medo.

\section{Abstract}

We live in a time when malaise is radicalized and expressed in manifestations of intolerance. We seek to support intolerance as a result of the malaise present in the constitution of borders in the social and subjective fields and in the modes of circulation between territories. There is in intolerance a position of the subject ruled by the consenting ignorance of the complexities at stake-social, political, historical, cultural, linguistic or psychic. In this operation, there is a tripod: paranoia as the matrix of the knowledge of liberal logic, which holds the imaginary of a society under threat and incites the fear of alterity as central political affection and hatred as an adjunct. In an identity logic, which lends itself to a certain 'obturation' of the adventure of desire, the other becomes synonymous with an enemy or object of radical indifference that advocates its disappearance. Ignorance obscures the ambivalence at the heart of the subject and aggressiveness that inhabits each one. But if, on the one hand, hatred or the desire for destruction is constitutive; on the other, it is the subject's choice and responsibility to put it into action.

Keywords: intolerance; policy; psychoanalysis; hate; fear. 


\section{Resumen}

Vivemos en un tiempo en que el malestar se radicaliza y se manifiesta bajo la forma de intolerancia. Buscamos sujetar la intolerancia como fruto del malestar presente en la constitución de las fronteras en los campos social y subjetivo y en los modos de circulación entre territorios. En la intolerancia hay una posición del sujeto basada en la ignorancia permitida de las complexidades en juego - sociales, políticas, históricas, culturales, lingüísticas o psíquicas. En esa operación hay un trípode: la paranoia como matriz del conocimiento de la lógica liberal, que mantiene el imaginario de una sociedad bajo amenaza y provoca el miedo de la alteridad como afecto político central y el odio como secundario. En una lógica de identidad, que se ofrece a cierta 'obturación' de la aventura del deseo, el otro se transforma en sinónimo de enemigo u objeto de una indiferencia radical que preconiza su desaparecimiento. La ignorancia oscurece la ambivalencia que está en el centro del sujeto y de la agresividad que vive en cada uno. Pero, si de un lado, el odio o el deseo de destruición son constitutivos, de otro, es de elección y responsabilidad del sujeto ponerlo en acto.

Palabras clave: intolerancia; política; psicoanálisis; odio; medo.

\section{Résumé}

On vit à une époque où le malaise va au extrême et s'expresse par des manifestations d'intolérance. On cherche à soutenir l'intolérance comme conséquence du malaise présent dans la constitution des frontières chez les domaines social et subjectif et dans les modes de circulation entre domaines. Dans l'intolérance, on trouve une position du sujet marquée par l'ignorance des complexités en jeu - sociales, politique, historiques, culturelles, linguistiques ou psychologiques. Dans cette opération, il y a un trépied: la paranoïa comme source de connaissance de la logique libérale, laquelle maintient l'imaginaire d'une société sous la menace et incite à la peur de l'altérité comme affection politique et incite aussi à la haine. Dans une logique d'identité, qui se prête à certaines «coupes» de l'aventure du désir, l'autre devient un synonyme d'ennemi ou un objet d'une indifférence radical que permet sa disparition. L'ignorance obscurcit l'ambivalence qui est au cour du sujet et de l'agressivité qui habite à chacun. Mais si, d'un côté, la haine ou le désir de destruction sont constitutives; de l'autre, du sujet du choix, et de la responsabilité de les mettre en action.

Mots-clés: intolérance; politique; psychanalyse; haine; peur.

Vivemos, nos últimos anos, o que já se define como 'ascensão da extrema-direita' (Krugman, 2017), assim como uma 'nova onda conservadora' (Welle, 2017) em diversos países. No Brasil, cresce uma população de jovens eleitores tendentes ao revisionismo histórico e à intolerância política, bem como favoráveis à eleição de candidatos à presidência do país proliferadores de discursos de ódio e antidemocráticos.

Torna-se, assim, imprescindível retornarmos ao tema da intolerância como fruto do mal-estar presente nos territórios, em suas bordas e em sua política. Se, de um lado, as fronteiras estabelecem limites e separações, de outro podem estender-se até a fragmentação impeditiva de uma análise conjuntural dos fenômenos. Ao se perder a complexidade da constituição das fronteiras (entre países, culturas, pessoas), com dimensões históricas, sociais, políticas, linguísticas e culturais, as fronteiras se tornam a questão em si, e se limitam ao embate, ao modo de fronts de guerra. A circulação da alteridade, dentro ou entre territórios, passa a produzir respostas identitárias, massificantes e intolerantes.

No presente artigo, apresentaremos reflexões pautadas na psicanálise acerca da predominância da intolerância na problemática relacionada ao território e suas fronteiras e bordas. Vamos tratar o tema no recorte da articulação e tensão entre a lógica identitária e a lógica desejante, presentes nas vicissitudes da construção do território e na manutenção de suas fronteiras sociais, linguísticas, discursivas ou psíquicas.

A lógica identitária estabelece fronteiras rígidas entre eu e o outro, podendo favorecer radicalismos e intolerâncias, enquanto a lógica desejante coloca em perspectiva a responsabilidade e o assentimento subjetivo, em uma articulação complexa entre desejo e cena política. Buscamos sustentar que, na intolerância, prepondera a lógica identitária que favorece uma massificação sob o semblante de uma democracia para quase todos.

Entendemos que a intolerância está pautada pelo engessamento do outro, do próximo, por ser uma ameaça à liberdade ou por desaparecer sob sua (des)importância, ao não referendar os modos de existência do grupo hegemônico. Nessa medida, há na intolerância uma posição do sujeito pautada pela ignorância consentida das questões em jogo. Buscamos sustentar que o império da intolerância é construído pela massificação regida pela ignorância, uma das paixões do ser que, ladeada por amor e ódio, torna a alteridade um sinônimo de estrangeiro-inimigo. 
Nossa argumentação será que a lógica liberal favorece essa posição do sujeito, na medida em que manipulao desamparo, transformado em medo da alteridade, que, então, torna-se sinônimo de estrangeiro e inimigo, ou objeto de uma indiferença radical que preconiza o seu desaparecimento. Nessa operação há um tripé: a lógica liberal está apoiada no sujeito da ciência, que tem a paranoia como matriz do conhecimento humano (Lacan, 1964/1988). Essa é também a matriz de uma sociedade sob ameaça e que tem, por sua vez, o medo como afeto político central (Safatle, 2016) e o ódio (Rosa, 2016) como coadjuvante.

Iluminados pela psicanálise e por seus constructos teóricos e clínicos, apresentaremos considerações sobre o mal-estar na constituição das fronteiras nos campos social e subjetivo e nos modos de circulação entre territórios, aquele que se expressa em manifestações de intolerância. Nossa metodologia de investigação psicanalítica nos permite explorar esse tema sem abrir mão de sua polissemia. Trata-se de um método que surge de nossas experiências de atendimento psicanalítico em territórios marcados pela exclusão social e política; da escuta dos sujeitos em situações sociais críticas.

Este método, que em outro lugar nomeamos como 'psicanálise implicada' (Rosa, 2013a, 2016), consiste em lidar com as fronteiras na prática e na investigação psicanalítica. $\mathrm{O}$ atendimento de população imigrante, migrante não documentada $\mathrm{e}$ refugiada (Rosa, 2002), nos mostrou que a psicanálise implicada é "[...] aquela constituída pela escuta dos sujeitos situados precariamente no campo social" (Rosa, 2013a) e também em constante interlocução com outros campos. A psicanálise implicada não se constitui enquanto disciplina autônoma, pois o avançar da teoria é tributário da sua capacidade "[...] de se interrogar quanto às suas fronteiras com atividades vizinhas" (Zygouris, 2011, p. 6). Além disso, ela não tem a pretensão de esgotar a compreensão dos fenômenos que investiga, pois seu interesse concentra-se no exercício de investigação da dimensão inconsciente, seja no consultório, na instituição,seja no campo social.

Assim sendo, considerando a complexidade do tema, este artigo pretende discutir as bordas, os impasses no laço com o outro ao constituir territórios que não sejam fronts de guerra, mas fronteiras com o reconhecimento da alteridade e manutenção do laço social. Antes de seguirmos, no entanto, advertimos que não há uma equivalência simples entre identidades e massas ignorantes, que só poderiam ser superadas pela solução individual, falsamente equivalente a desejo e responsabilidade.

\section{Fronteiras e Paranoia na Constituição de um Território para o Sujeito}

As vicissitudes da construção do território e suas fronteiras e bordas — sociais, linguísticas, discursivas ou psíquicas —, assim como os modos de circulação entre territórios, atualizam-se no contexto contemporâneo. Esse momento é caracterizado pela lógica capital do consumo, que 'globaliza' a economia e as culturas ao mesmo tempo em que enrijece as fronteiras, como marcam os muros de concreto que impedem a circulação de pessoas para que não usufruam das 'benesses econômicas' dos países economicamente fortes. O contexto tenso e violento tem processado, na constituição psíquica e no laço social, impasses tematizados pelos jovens imigrantes particularmente, que se deparam com a condição trágica de sujeitos exilados, desenraizados de si, constituídos pelo desconhecimento enigmático do desejo e sem direções pré-instituídas. Nesse contexto, o trabalho de implicação na construção de modos singulares de pertencimento social, de elucidação e de atualização dos referenciais simbólicos da cultura, torna-se tarefa por vezes vivida como impossível.

O trabalho de constituição do sujeito processa-se no contexto do 'conhecimento paranoico' vertente do advento e preponderância do sujeito da ciência, um dos três dispositivos nos quais a obra lacaniana se apoia em sua crítica da sociedade. O sujeito da ciência, sob a perspectiva lacaniana, caracteriza a ciência moderna como um discurso inaugurado pelo cogito, através da extração de uma certeza - é "[...] o sujeito cartesiano que aparece no momento em que a dúvida se reconhece como certeza” (Lacan, 1964/1988, p. 122). Segundo Roudinesco (1988), esses dispositivos são:

distribuídos nos registros do simbólico, imaginário e real: o mito edipiano, como o fundador das sociedades modernas; a função da identificação, como presente na Psicologia das Massas e problema para a formação das sociedades de psicanálise; e, por fim, neste século, o advento do sujeito da ciência, fenômeno fundamental, segundo Lacan, cuja irrupção foi mostrada no nazismo (1988, p.478, ênfase nossa).

E, complementa Lacan (1978), "o crescimento de um mundo organizado sobre todas as formas de segregação, eis em que a psicanálise cresceu mais sensivelmente ainda" (p. 22). É nesse debate que a premissa paranoica é anexada ao conhecimento humano por Lacan, em que se destaca a função do eu, sempre no registro imaginário: é pelos olhos do outro que conhecemos o mundo e, concomitantemente, nos desconhecemos. A paranoia passa a figurar como precondição para o conhecimento e a designar a estrutura do eu, permitindo a Lacan atribuir a precondição paranoica ao conhecimento humano.

Gonçalves e Teixeira (2015) destacam que será a partir da análise do caso de Aimée que Lacan vai propor a paranoia como uma síntese discordante da personalidade de desenvolvimento normal, como um fenômeno cognitivo total, ou seja, como fenômeno do conhecimento. A paranoia torna-se uma modalidade de conhecimento na constituição histórica das inter-relações 
entre o indivíduo e seu meio, endereçando a questão à interface com o campo social. Segundo esses autores, a expressão 'conhecimento paranoico' foi introduzida por Jacques Lacan nos anos que sucederam à sua tese de doutorado, em 1932.

A primeira referência ao termo ocorre em uma resenha sobre o livro de Minkowski, Compte rendu de le temps vécu (Lacan, 1935), mas as bases de sua construção encontram-se em O estádio do espelho como formador do Eu (Lacan, 1998b). O termo ganha ainda um acréscimo em Formulações sobre a causalidade psíquica (Lacan, 1998a), e é retomado em Some reflections on the ego (Lacan, 1953), sendo esses trabalhos referentes ao período que concerne à elaboração de sua teoria do imaginário. Contudo, a tese é resgatada no Seminário livro 3: O Outro e a psicose (Lacan, 2002), quando o autor já opera sua leitura teórica à luz do estruturalismo, dimensionando o registro do simbólico. Por fim, é citado pela última vez em Subversão do sujeito e dialética do desejo no inconsciente freudiano (Lacan, 1998c) (Gonçalves \& Teixeira, 2015, p.1).

Retomando nossa discussão sobre os sujeitos desenraizados de si, constituídos pelo desconhecimento enigmático do desejo e sua ignorância, demarcamos a importância do conhecimento no marco paranoico, sem participação do sujeito e sua enunciação, na produção desse fenômeno. Contribui para o desenraizamento do sujeito o modo como o sistema cartesiano centra-se na consciência de si em aliança à paixão pela ignorância da divisão subjetiva que o constitui. Tais condições dão suporte ao individualismo, em que o sujeito fica reduzido à consciência de si e se situa fora da referência ao desejo e à enunciação. Lembrando a preocupação de Lacan acima citada - em que se produz um mundo organizado sobre todas as formas de segregação, cuja irrupção foi mostrada no nazismo - , há um preço a se pagar pelo racionalismo de uma sociedade liberal. A ameaça de uma falta de 'referência', de um possível território comum, pode possibilitar a constituição de uma territorialidade circunscrita por uma demanda fixa e sem possibilidade de dialetização, alienada no Outro.

Na proposta de Lacan (1969-70/1992) sobre o discurso do capitalista também é possível visualizar a dinâmica do racionalismo liberal. Dado por uma inversão do 'discurso do mestre' - no qual o S1 (significante-mestre) ocupa o lugar de agente de discurso que é sustentado pelo sujeito barrado no lugar da verdade - , o discurso capitalista tem o sujeito ocupando a função de agente, sustentado pelo significante mestre no lugar da verdade, mas não estabelecendo qualquer relação com o outro nem estabelecendo relação com o saber. O que significa que, no discurso do 'mestre moderno' (Lacan, 1969-70/1992), o sujeito pode ser tido como ‘verdade absolutizada' (Ferreira, no prelo), em que não há espaço para laços e se constitui apenas em sua alienação com o significante-mestre, sem espaço, como dito, para a 'dialetização'.

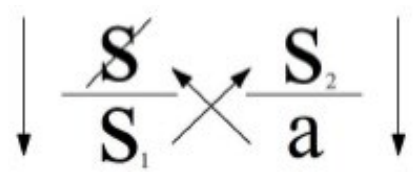

\section{Discurso do Capitalista}

A construção e manutenção de fronteiras torna-se questão aguda na sociedade liberal, estruturada sobre a noção de indivíduos mediados pela lógica capital do consumo. Segundo Safatle (2016), a própria lógica liberal produz a imagem do outro, do próximo, como um invasor em potencial, isto é, potencialmente uma ameaça à total expressão da "minha liberdade", ou da 'verdade absolutizada', como marcamos. Aí encontramos o germe da sociedade pautada pelo conhecimento paranoico (Lacan, 1998c), ressentida (Koltai, 2004), isto é, uma sociedade sob ameaça, que tem o medo como o afeto político central (Safatle, 2016) e o ódio (Rosa, 2016) como coadjuvante.

Com essa sustentação pensamos que a constituição de territórios e fronteiras opera na tensão entre a lógica identitária e a lógica desejante e, para sustentar essa posição, destacamos esses processos de constituição subjetiva. Essa hipótese toma como referência os processos da constituição subjetiva, tanto na adolescência como nos processos de imigração ou errância, nos quais verificamos que momentos de deslocamento promovem a suspensão de certezas simbólicas e imaginárias do Eu e, para alguns, a suspensão da função pacificadora e estabilizadora do Eu. O Eu, como apoio identitário, tem função de apaziguamento da angústia.

A desestabilização do Eu pode resultar na revisão e reposicionamento perante leis e valores, o que favorece a dimensão desejante. Em contrapartida, dificulta marcar o lugar de onde se podem estabelecer laços com o outro. Os abalos identificatórios afetam especificamente o eu, seja no registro imaginário (eu ideal), seja no registro simbólico (ideal do eu). "Os abalos identificatórios podem ser libertários, mas também desorientadores e, nesse caso, facilitam a aceitação do mínimo para a subsistência, dispensados os artifícios narcísicos, que podem tomar forma de conformidade e submissão" (Rosa, 2011, p.37).

Estar pressionado, desenraizado, pode levar o sujeito a se emaranhar nas garras do instantâneo, no reagir em vez do agir, como uma tentativa de se amparar em alguma referência que supostamente poderia representar um ponto de apoio, uma forma de estar menos sozinho na sua angústia (Tatit \& Rosa, 2013, p. 455). Vemos presente na formação de grupos 
potencialmente intolerantes algo da lógica identitária que se presta a certa 'obturação' da aventura do desejo. Há uma tendência narcisista nesses grupos que, geralmente, são atraídos pela proposta de igualdade e novo sentido no mundo, pela vivência da territorialidade comum, e pelo desenvolvimento de um código de linguagem próprio, em que os atos de rejeição dos "mais fracos", "desgarrados" ou "diferentes" parecem legítimos e morais.

O desamparo social e subjetivo articula-se às balizas políticas para favorecer a intolerância. A questão é que as respostas oferecidas pelo Estado não são apenas ilusórias, como também impossíveis. Em sua impossibilidade de oferecer a segurança social paranoicamente almejada, o desamparo, medo e ódio passam a operar como dispositivos sinalizadores da ameaça social. Através desses dispositivos, alguns de seus elementos passam a encarnar a frustração do anseio por controle da violência e transformam-se em objeto, para o qual o medo social é dirigido. Esses avatares variam de acordo com o tempo, espaço e conjuntura, por exemplo. Assim sendo, o político passa a significar a gestão do objeto de medo e "a política se transforma assim na gestão da fobia" (Safatle, 2016, p. 56), já que se torna central que esse objeto permaneça como uma aterrorização constante da segurança e do controle social.

No entanto, partilhar certo sentimento de pertencimento a um grupo em que todos são tidos, tratados e nivelados como 'iguais' pode imprimir às massas um semblante democrático, ou seja, desmentindo que está assentado na exceção. A ideologia, por exemplo, funciona para manter a ilusão de igualdade, quando, na verdade, pode haver o exercício de um poder autocrático. A fraternidade é desde sempre segregação, essa é a sua origem. Ela aponta o que quer encobrir, a condição trágica do sujeito, ou, como Lacan (1969-70/1992, p. 107) sugere, toda a energia gasta tentando nos colocar enquanto 'fraternidade' coloca em evidência o que não somos. A referência é Totem e tabu (Freud, 1912-13/2006a), em que Freud marca que o laço fraterno brota da expulsão da horda do pai. O efeito desse laço é o parricídio, a proibição (o tabu) e a culpa (totem), que compartilham um mesmo horizonte: o apagamento da segregação, da desterritorialização.

Os modos de gestão da sociedade retomam a questão da sociedade de massas, dessa vez centrada no desamparo, manifestado via desterritorialização e medo, elementos na constituição e gestão de um território para o sujeito. A ameaça da desterritorialização, de uma falta de 'referência', e a construção de um possível território comum podem possibilitar a constituição de uma territorialidade circunscrita por uma demanda fixa e sem possibilidade de dialetização.

\section{Intolerância: Ignorância e Extimidade}

A fórmula da intolerância não é nova. É preciso eleger o outro-inimigo para que se fortaleça o narcisismo - 'narcisismo das pequenas diferenças', como nomeou Freud (1918[1917]/2006b, p. 206). Podemos aqui também nos referir à questão da ignorância que se manifesta sob a capa do ressentimento, que diz de uma posição do sujeito em que qualquer abalo narcísico — ou falta - é vivido como um prejuízo provocado pelo outro; em que o outro é responsabilizado pelo acesso limitado ao gozo, ante a ilusão de acesso ao gozo sem qualquer preço a responder, como um direito natural e adquirido (Rosa, 2016), como marca o discurso do capitalista.

A intolerância é oblíqua à distinção entre gozo e desejo, o que faz com que se confunda nas massas o que é mal-estar e o que é ressentimento, Em outras palavras, na intolerância não conseguimos distinguir o que é condição material (desamparo social), o que é o desamparo constitutivo do sujeito, que o lança ao laço com o outro, e o que é ideologia (ódio ao estrangeiro), e assim temos a fórmula do fascismo, como aponta Reich (1933/1988).

A Psicologia de massas oferece uma via de explicação para as discrepantes divergências entre os discursos ideológicos fascistas e as bases materiais socioeconômicas a partir dos quais ascenderam os movimentos fascistas. Como entender que, em uma situação de crise, em vez de o pensamento das massas se dirigir para uma 'consciência de classe', na qual reconheceriam sua situação de exploradas, estas podem, ao contrário, contribuir para a ascensão do fascismo? Reich indica a possibilidade de que exista uma clivagem entre a situação material econômica e a estrutura psíquica das massas populares (Reich, 1933/1988, p. 35), isto é, entre a distribuição econômica e situação ideológica da prática política (Reich, 1933/1988, p. 34).

$\mathrm{Na}$ 'psicologia do fascismo', o que se tem é uma manipulação, pois aquilo que "é visto ingenuamente como irracionalidade 'natural' das massas é produzido por técnicas calculadas racionalmente" (Adorno, 1975, p.10). Segundo Adorno, "as predisposições psicológicas não são a causa real do fascismo; acontece antes de o fascismo definir uma área psicológica que pode ser explorada com sucesso pelas forças que o promovem por razões de interesse próprio totalmente não psicológicas" (Adorno, 1975, p.11). Assim, o fascismo estaria na contramão da própria psicanálise freudiana, em sua vertente de negatividade, justamente por abolir a possibilidade de realização de uma emancipação do sujeito, já que permitiria "a expropriação do inconsciente pelo controle social, em vez de fazer os sujeitos conscientes de seu inconsciente" (Adorno, 1975, p.11). E, ainda, acrescentando a psicanálise, a estratégia é fazer com que o sujeito suponha que se ele não goza é porque o outro o faz em seu lugar, colocando-se na posição de vítima ressentida — é o que Koltai (2004) denominou de politização do gozo. 
Segundo Arendt (1989), somos ressentidos contra tudo que nos é dado, inclusive nossa própria existência; ressentidos contra o fato de que não somos criadores nem do universo nem de nós mesmos. Levados por esse ressentimento fundamental a não ver o menor sentido no mundo tal como se apresenta, o homem moderno proclama que tudo é permitido e crê secretamente que tudo é possível. Arendt ainda afirma que a gratidão é a única alternativa ao niilismo do ressentimento - a gratidão fundamental pelas coisas elementares que nos são dadas: a própria vida, a existência do homem e o mundo.

Por outro lado, a reverência apaixonada ao líder, instituindo-o no lugar do ideal do eu, autoriza os indivíduos de um grupo social a obedecê-lo de forma acrítica e, imaginando-se igualmente amados por ele, identificam-se uns com os outros, pois estão todos identificados com a posição de 'filhos' do grande Pai. É esse processo, de acordo com a teoria freudiana, que pode levar os indivíduos a abdicar de sua capacidade de pensar por si - compartilhando a crença na doutrina proposta pelo líder, que geralmente divide o mundo em bons (os adeptos da "causa" - nós) e maus (todos os demais - eles) - processo capaz de possibilitar atos que, se não fizessem parte do grupo, possivelmente jamais teriam coragem de praticar.

A dispersão pulsional, o enigma infindável, parece momentaneamente suspenso e a dúvida angustiada parece ter sido abonada para dar lugar a um direcionamento. A vibração dessa intensa energia pode servir como catalisadora, dando vazão ao ressentimento, dissolvendo barreiras sociais e morais, e impulsionando forças destrutivas das quais não se tem consciência. O sentimento de superioridade para com os estranhos ao grupo contrasta com a obediência servil a seus interesses.

Na apresentação do Discurso da servidão voluntária (1549/1997) o tradutor menciona uma observação memorável de outro tradutor da obra, Manuel J. Gomes que dizia que em nossos tempos a submissão é doce como refrigerante e a liberdade demasiado amarga (1549/1997). Logo, os jovens inseguros, às voltas com o trabalho de desvendar alguma direção digna para a vida, podem trocar essas angústias pelas 'facilidades' das certezas e da submissão ao líder e, consequentemente, ao grupo. La Boétie se espanta:

Uma situação impressionante, sem dúvida, e, no entanto, tão corriqueira que o certo seria nos lamentarmos muito mais do que nos surpreendermos, vendo milhões de homens servirem miseravelmente, com o pescoço sob jugo, sem ser constrangidos por um grupo de homens mais numerosos e mais fortes, mas de algum modo (e é o que parece) encantados e enfeitiçados pelo nome de um só homem, cujo poder não devem temer, porque ele é só um, e cujas qualidades não devem amar, pois ele é desumano e cruel. (La Boétie, 1549/1997, p.17).

Como dizia Arendt (1999) em 1961, por ocasião do processo Eichmann, da 'banalidade do mal', o carrasco nazista não era um monstro, mas um homenzinho insosso como tantos que existem em toda parte, que ficam cegos e surdos de prepotência, rompendo a relação com o outro-diferente e até mesmo com os apelos vindos dos vínculos pessoais. Encontramos em Arendt a formulação derradeira da problemática que Reich (1933/1988, p. 12) apenas sondava, ao afirmar que a manifestação social do fascismo, em termos freudianos, é o sinal incontestável da presença do fascismo no psiquismo, ou seja, em cada um de nós.

A questão é que o ressentido não se vê como agente no jogo de poder em que está colocado. A sua posição convoca a tutela de um saber, instituindo-se o império da mais insidiosa das paixões do ser: a ignorância, leviandade em que o sujeito não se responsabiliza — como afirma Žižek (1992), apoiado na ideia de cinismo de Sloterdijk (1988/2012): mais além da premissa de que não sabe o que faz, observa-se que sabe, mas faz mesmo assim. Em vez da dialetizacão que abre para a complexidade e opera pela presença do enigma e pela determinação do desejo de saber, temos, na intolerância, a produção de dicotomias acompanhadas da certeza opaca própria da ignorância.

Entendemos que a intolerância supõe uma partição entre o eu e o outro como o bom e o mau, em que a alteridade se torna sinônimo de estrangeiro-inimigo. Recalca o fundamento comum e deixa predominar a tônica paranoica do narcisismo. O narcisismo é constitutivo de todo sujeito, mas pode ser convocado em um laço totalitário que procura o apagamento, a imobilização e neutralização do outro, impondo a homogeneização e a subtração da diferença, diz Rosa (2013b). Outra modalidade de laço com o outro será a indiferença, que decreta o desaparecimento do outro do laço social, literal ou na forma de uma existência sem direitos e cidadania.

Aqui, política e psicanálise nos ajudam a entender. A ignorância opera obscurecendo a ambivalência que está no cerne do sujeito e da agressividade que habita cada um. Amor e ódio são dirigidos ao mesmo objeto e o ódio está sempre presente como potencialidade. A violência é, fundamentalmente, fratricida. Outro ponto: “o objeto do ódio não é inteiramente externo ao sujeito - é extimo - externo e íntimo; a impressão de que o outro é inteiramente externo a mim é uma produção paranoica do sujeito" (Rosa, 2013b, p. 95). Dessa forma, não há vencedores na destruição do outro, pois o objeto destruído não lhe é inteiramente externo e a destruição retorna de vários modos, seja sobre o sujeito, seja sobre a comunidade a que pertence, ressoando por gerações.

Desse modo, destacamos que: se, de um lado, o ódio ou o desejo de destruição é constitutivo, de outro, é de escolha e responsabilidade do sujeito colocar em ato - mesmo considerando que a ordem social atravessa os sujeitos, ela também os ultrapassa, pois está em jogo não só a trama pulsional do sujeito, mas também a trama política, ideológica ou cultural de uma 
dada comunidade que sustenta tal ato. Desse modo, a intolerância torna-se um fato social, também de responsabilidade coletiva. Com isso, para compreender a intolerância não basta a vida de cada um, ou seus aspectos psíquicos, mas é fundamental que se atente à forma como se enreda a história do grupo ao qual pertence e também à história social de seu país.

\section{Considerações Finais}

Em suma, se as fronteiras do sujeito e do grupo demarcam e separam territórios, também são, elas próprias, constituintes do território. Pensar em territórios é pensar em pressupostos éticos que transcendem o campo ideológico, dizendo respeito antes ao domínio da política (o laço com os outros) e da cultura (a relação ao Outro). O desafio versa sobre como contrapor outras formas de expressão da vida para além desta que nos torna seres privados, tanto da presença dos outros como da realidade que advém de um mundo compartilhado.

A radicalidade da separação entre os territórios apenas indica pretender abolir ou esquecer o caráter histórico e político de sua constituição. Fazer da fronteira um front de guerra gera um mundo medroso e paranoide, de exclusões, de intolerância. Nesse caso, nada além do que está estabelecido como paradigmático desse território pode ser acolhido, sendo tomado como uma perturbação, como diferente, e, com essas exclusões, as fronteiras imaginárias consolidam tomar o estrangeiro como inimigo e naturalizam sua exclusão do território.

Esse modo de organização política está em contraponto à noção de experiência. A experiência permite partilhar uma narrativa abrindo mão do seu sentido último e oferece um espaço aberto ao sujeito para que ele viva a aventura de exilar-se de si, de inventar-se outro, de voltar-se não idêntico. Será no locus do coletivo que a experiência poderá se produzir. A concepção de experiência articula sujeito e coletivo, pois, segundo Agamben (2005), significa, necessariamente, voltar a acionar o infantil, esse locus atemporal que institui o ponto de abertura para o singular da enunciação que contrasta com as frases genéricas de efeito. Essa dimensão desnaturaliza a separação entre singular ao coletivo, entre sujeito e política que, aliás, está posta desde Freud, no próprio Psicologia das Massas, quando ele afirma a inerente relação entre o individual e o social.

No entanto, o que podemos compreender na lógica da intolerância e na sua parceira, a ignorância, é que existe uma estagnação na circulação simbólica e imaginária do campo social e do apagamento da política, pois ela existe porque e quando "a ordem natural dos reis pastores, dos senhores de guerra ou das pessoas de posse é interrompida por uma liberdade que vem atualizar a igualdade última na qual assenta toda ordem social" (Rancière, 1996, p.31). O que significa que política não acontece sempre e que a gestão da intolerância e da ignorância não se relaciona com política, mas com o poder, com gestão de interesses.

Entre massa e indivíduo existe o desafio posto em cada época, em cada sujeito, de atualizar a civilização, num processo que não o exime de se posicionar em relação à civilização que herdou e a que deve ou não assentir. Na transmissão da civilização, estamos advertidos da incidência das discursividades e, portanto, da discursividade política, que dizem, de certo modo, das relações de poder e de governança. Sob essas circunstâncias, cabe ao sujeito separar, no seu assentimento à cultura, a alienação estrutural do sujeito ao discurso do Outro, da alienação ao discurso social e ideológico. Essa alienação e esse enredamento podem ser elucidados pela via da historicização dos laços sociais em certos grupos sociais, o que se dá pelo resgate da memória na e pela experiência compartilhada.

\section{Referências}

Adorno, T. (1975). A teoria freudiana e o modelo fascista de propaganda. Link

Agamben, G. (2005). Infância e história. Belo Horizonte: UFMG.

Arendt, H. (1989). Origens do totalitarismo. São Paulo: Companhia das Letras.

Arendt, H. (1999). Eichmmam em Jerusalém. São Paulo: Companhia das Letras.

Ferreira, P. P. (no prelo). Coletividade e histeria: Psicanálise e manifestações sociais.

Freud, S. (2006a). Totem e tabu. In J. Strachey (Ed.), Edição Standard Brasileira das Obras Psicológicas Completas de Sigmund Freud (Vol. 13, pp. 13-68). Rio de Janeiro: Imago. (Originalmente publicado em 1913[1912-13]).

Freud, S. (2006b). O tabu da virgindade (Contribuição à psicologia do amor III). In J. Salomão (Ed.), Edição Standard 
Brasileira das Obras Psicológicas Completas de Sigmund Freud (Vol. 11, pp. 199-215). Rio de Janeiro: Imago. (Originalmente publicado em 1918[1917]).

Gonçalves, S. F., \& Teixeira, A. M. (2015). Da paranoia do conhecimento à psicose: Uma travessia teórica no texto de Lacan. Ágora, 18(1), 101-113. DOI: 10.1590/S1516-14982015000100008

Koltai, C. (2004). O Ressentimento entre intensão e extensão. Textura, 4(4), 9-12.

Krugman, P. (2017). A ascensão da extrema-direita. Link

La Boétie, É. (1997). Discurso da servidão voluntária ou o contra um (M. J. Gomes, Trad.). Lisboa: Antígona. (Originalmente publicado em 1549). Link

Lacan, J. (1935). Le temps vécu: Études phénoménologiques et psycho-pathologiques. Recherches philosophiques, (4), 424-431.

Lacan, J. (1953). Some reflections on the Ego. Int J Psychoanal, 34(1),11-7.

Lacan, J. (1978). Proposition du 9 octobre 1967 [première version]. Analytica, (3),13-26. Link

Lacan, J. (1988). O seminário, livro 11: Os quatro conceitos fundamentais da psicanálise. Rio de Janeiro: Jorge Zahar. (Originalmente publicado em 1964).

Lacan, J. (1992). O seminário, livro 17: O avesso da psicanálise. Rio de Janeiro: Jorge Zahar. (Originalmente publicado em 1969-70).

Lacan, J. (1998a). Formulações sobre a causalidade psíquica (1946). In J. Lacan, Escritos (pp.152-194). Rio de Janeiro: Jorge Zahar.

Lacan, J. (1998b). O estádio do espelho como formador da função do Eu (1949). In J. Lacan, Escritos (pp.96-103). Rio de Janeiro: Jorge Zahar.

Lacan, J. (1998c). Subversão do sujeito e dialética do desejo no inconsciente freudiano (1960/1998). Rio de Janeiro: Jorge Zahar.

Lacan, J. (2002). O Seminário livro 3: O Outro e a psicose (1955-56). Rio de Janeiro: Jorge Zahar.

Rancière, J. (1996). O desentendimento: Política e filosofia. São Paulo: Editora 34.

Reich, W. (1988). Psicologia de massas do fascismo. São Paulo: Martins Fontes. (Originalmente publicado em 1933).

Rosa, M. D. (2002). Uma escuta psicanalítica das vidas secas. Revista Textura, 2, 42-47.

Rosa, M. D. (2011). O jovem na cena social: a relação identificação, ato e inserção social. In G. Biasoto Jr, \& L. A. P. Silva (Orgs.), Políticas Públicas em questão (pp. 35-46). São Paulo: Fundap.

Rosa, M. D. (2013a). Psicanálise implicada vicissitudes das práticas clinicopolíticas. Revista da Associação Psicanalítica de Porto Alegre, 41, 29-40.

Rosa, M. D. (2013b). Imigração forçada: a dimensão sócio-política do sofrimento e a transmissão da história. In M. D. Rosa, T.T. Carignato, \& S. L. S. Alencar (Orgs.), Política e desejo: Desafios e perspectivas no campo da imigração e do refúgio (pp.83-98). São Paulo: Editora Max Limonad.

Rosa, M. D. (2016). A clínica em face da dimensão sócio-política do sofrimento: Psicanálise, política e cultura. São Paulo: 


\section{Escuta/ Fapesp.}

Roudinesco, E. (1988). História da psicanálise na França. Rio de Janeiro: Zahar.

Safatle, V. (2016). O circuito dos afetos: Corpos políticos, desamparo e o fim do indivíduo (2a ed.) Belo Horizonte: Autêntica.

Sloterdijk, P. (2012). Crítica da razão cínica. São Paulo: Estação Liberdade. (Originalmente publicado em 1988).

Tatit, I., \& Rosa, M. D. (2013). Errância e isolamento: as dimensões de desejo e de gozo da solidão. Psicologia em Revista (Online), 18, 446-457. DOI: 10.5752P.1678-9563.2012v18n3p446

Welle, D. (2017). A nova onda conservadora o Brasil. Link

Žižek, S. (1992). Eles não sabem o que fazem: O sublime objeto da ideologia. Rio de Janeiro: Jorge Zahar.

Zygouris, R. (2011). Psicanálise e psicoterapia. São Paulo: Via Lettera.

\section{Endereço para correspondência}

Miriam Debieux Rosa

Email: debieux@terra.com.br

Diego Amaral Penha

Email: penhadiego41@gmail.com

Patrícia do Prado Ferreira

Email: ppferreira01@gmail.com 